\title{
Deontología periodística en materia de violencias contra las mujeres. ¿Quién elabora los documentos? Un estudio longitudinal desagregado por sexo sobre la autoría
}

\section{Journalistic deontology on violence against women. Who produces the documents? A longitudinal disaggregated study by sex on authorships}

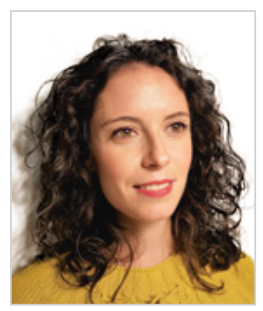

Aurora Edo Ibáñez. Licenciada en Periodismo por la Universidad CEU Cardenal Herrera (UCH CEU), actualmente es Investigadora en formación de la CEU Escuela Internacional de Doctorado (CEINDO) y beneficiaria de una ayuda FPU del Ministerio de Educación, Cultura y Deporte. Miembro del Proyecto I+D+i del MINECO Ref. FFI2013-42443-R y del Proyecto de la UCH CEU Ref. Indi 18/01. Integrante del Grupo de Investigación “Democracia deliberativa, Comunicación y Ciudadanía". Imparte la asignatura de Ética de la Comunicación en los Grados de Periodismo y Publicidad y RRPP de la UCH CEU. Ha participado en numerosos congresos internacionales y entre sus líneas de investigación destaca la deontología periodística, la violencia machista, la presencia de la mujer en el ámbito de la comunicación y el periodismo social. Ha trabajado como periodista en el Departamento de Comunicación del Instituto Municipal de Cultura y Juventud de Burjassot (Valencia). Universidad CEU Cardenal Herrera, Valencia, España

aurora.edo@uchceu.es

ORCID: 0000-0001-9718-7219

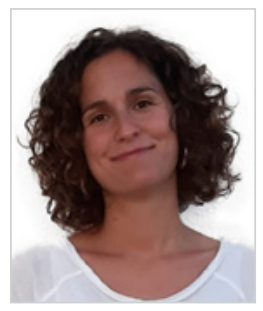

Belén Zurbano Berenguer. Doctora en Periodismo con mención internacional por la Universidad de Sevilla. Su Tesis Doctoral fue premiada por la Sociedad Española de Periodismo y el Ayuntamiento de Sevilla. Miembro del Grupo de Investigación Communication \& Social Sciences y del Gender, Economy, Politics ans Development Observatory (GEP\&DO). Ha impartido conferencias tanto en el contexto nacional como el internacional y cuenta con numerosas publicaciones en revistas de impacto. Ha impartido docencia en la Universidad del País Vasco/ EHU, en la Moulay Ismail (Meknès, Marruecos), en la de Colima (México), en la Pablo Olavide, en la Abdelmalek Essaâdi (Marruecos) y en la Universidad de Málaga, entre otras. Actualmente, es profesora en el Centro Universitario EUSA, dependiente de la Universidad de Sevilla. Sus principales líneas de investigación son la comunicación y la violencia de género, los medios de comunicación social y los movimientos feministas, el discurso periodístico y la teoría social feminista.

Universidad de Sevilla, España

bzurbano@us.es

ORCID: 0000-0002-2743-236X

Cómo citar este artículo:

Edo, A. y Zurbano-Berenguer, B. (2019). Deontología periodística en materia de violencias contra las mujeres. ¿̨uién elabora los documentos? Un estudio longitudinal desagregado por sexo sobre la autoría. Doxa Comunicación, 28, pp. 261-284.

https://doi.org/10.31921/doxacom.n28a14 
Deontología periodística en materia de violencias contra las mujeres ¿Quién elabora los documentos?...

Recibido: 22/01/2019 - Aceptado: 05/05/2019

\section{Resumen:}

El artículo se centra en el estudio de la autoría de la producción deontológica en materia de violencias contra las mujeres y medios en los contextos español y latinoamericano desde 1999 hasta 2018, a partir de una muestra de 58 códigos. Objetivos: analizar la autoría específica atendiendo a la variable de género para conocer el grado de implicación de mujeres y hombres y detectar si existe relación entre el género de los autores de los códigos y el nivel de compromiso de estos. Metodología: empleo de técnicas de investigación empíricas para el estudio de la autoría, a partir del cual se han establecido cinco tipos: mujeres o mayoría de mujeres; hombres o mayoría de hombres; mixta; colectivo de mujeres; autoría institucional (se desconoce). Resultados: el 60\% de los códigos han contado con el asesoramiento de mujeres para su redacción, mientras que el 9\% se atribuye a hombres. En el 10\% han participado tanto hombres como mujeres de manera equitativa, el $7 \%$ pertenece, presuntamente, a colectivos de mujeres, y del resto (14\%) se desconoce su autoría. Además, esta diferencia cuantitativa guarda relación con el grado de compromiso de los códigos, es decir, los códigos atribuidos a mujeres ofrecen niveles de compromiso más elevados que los elaborados por hombres.

\section{Palabras clave:}

Violencias contra las mujeres; deontología; periodismo; códigos; autoría
Received: 22/01/2019 - Accepted: 05/05/2019

\section{Abstract:}

The article focuses on the study of the authorship of deontological production on violence against women and the media in Spanish and Latin American contexts from 1999 to 2018, based on a sample of 58 guidelines. Objectives: to analyse the specific authorship by gender to identify men's and women's degree of involvement and whether there is a relationship between the gender of the authors' of the guidelines and their level of commitment to them. Methodology: the use of empirical research techniques for the study of the authorship, from which five types have been established, women or majority of women, men or majority of men; mixed; a women's collective; and institutional authorship (unknown). Results: $60 \%$ of the guidelines were written with women's advice, while 9\% has been attributed to men. In 10\% of them men and women have participated equally, 7\% presumably belongs to women's collectives, and the remaining $14 \%$ of authorship is unknown. Moreover, this quantitative difference is related to the degree of commitment of the guidelines, that is, the guidelines attributed to women present higher levels of commitment than those produced by men.

\section{Keywords:}

Violence against women; deontology; journalism; guidelines; authorship

\section{Deontología periodística en materia de violencias contra las mujeres. Reflexiones sobre el estado de la cuestión}

Las violencias contra las mujeres (en adelante, $\mathrm{VVCMM}^{1}$ es un problema global actual de Derechos Humanos y generalizado en todas las sociedades que sufren diariamente las mujeres y niñas de todo el mundo. Es un fenómeno intemporal que no entiende de nacionalidades, etnias, culturas, religiones y costumbres -si bien es cierto, todos estos elementos pueden influir en las diferentes manifestaciones y formas que adquiere la violencia (Zurbano-Berenguer, 2015b)-, sino que se caracteriza por su universalidad.

Según la Organización Mundial de la Salud, la magnitud del problema a nivel internacional presenta una prevalencia del $30 \%$, es decir, una de cada tres mujeres que ha mantenido una relación íntimo-afectiva con un varón "ha sido víctima de

1 Por violencias contra las mujeres se entienden: "los actos y amenazas de tales actos, perpetrados en la vida pública y en la privada, que supongan peligro para la vida, la integridad, el cuerpo y la dignidad de las mujeres y las niñas y cuyo origen (explícito o no) está en la voluntad de control y sometimiento del género femenino existiendo un modelo socio-ideológico subyacente que determina los roles, actitudes e identidades de los sujetos sociales (hombres y mujeres) según su condición sexual y en la que influyen igualmente otras categorías como la clase, la raza, la etnia, la religión y la heteronormatividad, entre otras" (Zurbano-Berenguer, 2018: 83). 
violencia física y/o sexual por parte de su pareja" y el $38 \%$ de los homicidios femeninos cometidos a nivel mundial "se debe a la violencia conyugal" (OMS, 2013: 2). A nivel nacional el panorama no es menos desolador: desde el 1 de enero de 2003 -fecha en la que se comienza a registrar las cifras de manera oficial- hasta el 31 de diciembre de 2018, un total de 975 mujeres han sido asesinadas por sus parejas o exparejas, según el Portal Estadístico de la Delegación del Gobierno para la Violencia de Género.

Sin embargo, las cifras oficiales a nivel estatal no son sino la punta de un iceberg, ya que solo tienen en cuenta la violencia ejercida en el ámbito íntimo de la pareja, produciéndose, de esta forma, una conceptualización pobre y simplista del fenómeno y reduciendo las VVCMM al escenario de la afectividad (Zurbano-Berenguer y Liberia-Vayá, 2014). El problema de esta visión reduccionista no solo afecta a las mujeres víctimas que no se atreven a denunciar o no son agredidas en dicho entorno íntimo-afectivo, sino que se traslada a la ciudadanía, la cual no puede configurarse una idea aproximada de las violencias que sufren las mujeres al no disponer de datos completos y reales.

En este sentido, sobre el trabajo periodístico recae la responsabilidad de informar y formar a la opinión pública acerca de este grave problema donde se vulneran sistemáticamente los derechos humanos de las mujeres. Pero, de nuevo, la explicación mediática de la violencia no escapa a este reduccionismo, "pues la profesión periodística, como el resto de ciudadanía, no siempre está formada al respecto" (Menéndez, 2014: 55).

Por ello, diversos ámbitos académicos y profesionales han puesto el foco sobre la actividad diaria de los medios para mostrar su preocupación por la forma en la que son transmitidas y representadas las VVCMM. Una preocupación que toma como base las ausencias de las mujeres en los medios, el maltrato de sus identidades, la sexualización y objetualización de sus cuerpos y, en lo que a este trabajo respecta, una distorsión y simplificación de las violencias que sufren.

Así pues, en las últimas dos décadas, los estudios sobre el abordaje y tratamiento de estas violencias se han multiplicado. Trabajos como los de Simons y Khan (2018) o Simons y Morgan (2018) tratan sobre el cambio en la cobertura y en la configuración de los medios como herramientas de prevención de las VVCMM, siguiendo la línea de estudios anteriores que reflexionaban sobre las dinámicas de representación de género y de las agresiones generizadas (Anastasio y Costa, 2004; Wozniak y McCloskey, 2010; Roberto, McCann y Brossoie, 2013; Ross et al., 2018). En el actual contexto mediático la reflexión sobre estos contenidos en los medios digitales comienza a ser una nueva línea de investigación específica (Salter, 2013; Vega, 2018). También, la consolidación de esta preocupación en la esfera académica favorece los estudios contextuales como los de Ahmed (2014), que trabaja sobre las representaciones en Pakistán, Bullock y Cubert (2002), centrados en el estado de Washintong, o Fairbairn y Dawson (2013), quienes toman como contexto de análisis Canadá.

Igualmente, la atención prestada a la cobertura mediática de las VVCMM ha derivado en una publicación prolífica, desde finales del siglo XX, de documentos de carácter deontológico sobre cómo abordar sensible, ética y responsablemente este problema social. Dicha atención entronca con las evidencias científicas sobre la capacidad de influencia de los medios en general y, particularmente, sobre su influencia en el caso de las violencias ejercidas contra las mujeres.

"Esta influencia ya no se limita a las tradicionales funciones de informar y vertebrar la opinión pública, con ser las más importantes y aquellas con las que se sigue asociando en lo fundamental su actividad. A ella se han sumado las derivadas de 
Deontología periodística en materia de violencias contra las mujeres ¿Quién elabora los documentos?...

su creciente protagonismo educativo, socializador, creador de pautas de ocio y moda, etc. Como sabemos bien, los medios constituyen hoy uno de los grandes poderes de configuración simbólica de la sociedad en la que vivimos” (Aznar, 2005b: 20).

Además de socializadores y educativos, los medios se convierten en la fuente primaria de conocimiento en cuanto a las VVCMM, ya que en torno al 90\% de la ciudadanía afirma que es conocedora de esta realidad a través de los ellos (Ministerio de Sanidad, Política Social e Igualdad, 2011). Así, lo que los medios transmitan, y cómo, determinará el conocimiento que la población tenga acerca de este problema.

En este sentido, estudios como los realizados por Lorente ponen de manifiesto la relación entre la información periodística y la sensibilidad social con respecto a las VVCMM: “[...] conforme la sensibilidad aumenta, al año siguiente disminuyen los homicidios; pero cuando la sensibilidad baja, al año siguiente aumentan los asesinatos. Hay una relación inversa entre sensibilidad y número de homicidios" (2009: 55).

El foco puesto en la capacidad de incidencia que tienen los medios de comunicación supera las fronteras nacionales y existen numerosas discusiones académicas acerca de cuáles deben ser las responsabilidades intrínsecas del periodismo:

"Debido a que el público obtiene gran parte de su conocimiento acerca de la IPV² de los medios de comunicación es importante entender lo que las fuentes informativas, como los periódicos, trasladan en la actualidad. El papel que juegan los medios de comunicación en la formación de las concepciones públicas o conceptos erróneos acerca de la IPV lleva a la necesidad de un examen más a fondo de lo que los medios de comunicación realmente presenten al público. Si los medios no representan la IPV como importante, la sociedad en general, probablemente no la verá como importante" (Wozniak y McCloskey, 2010: 939) ${ }^{3}$.

Asimismo, Aznar añade otra causa a esta preocupación: desde finales de la década de los ochenta del pasado siglo "viene aumentando en los códigos la atención prestada a los nuevos problemas sociales" (2005a: 39) que suponen una amenaza para las democracias como el racismo, la xenofobia, el terrorismo o la propia violencia que sufren las mujeres. Para Aznar, estos códigos presentan dos novedades: a) se ocupan de temas o problemas concretos de la realidad informativa y b) su puesta en marcha y publicación procede en muchos casos de la iniciativa de la sociedad civil y no tanto del entorno profesional periodístico.

El impacto de la labor de los medios en la configuración de la opinión pública en este ámbito específico también se ha trasladado a la investigación académica y es posible encontrar estudios que abordan el análisis de los medios a partir de los manuales deontológicos existentes en materia de VVCMM: Gallego (2003), Aznar (2005b), López (2006, 2007 y 2008), Carballido (2007 y 2009), Martínez-Rodríguez (2010, 2011, 2012 y 2013), Bandrés (2011), Zurbano-Berenguer y Martínez Fábregas (2011), Zurbano-Berenguer y Liberia-Vayá (2013), Easteal, Holland y Judd (2015), Zurbano-Berenguer (2015a y 2015b), Peris (2016), Sutherland et al. (2016), Edo (2017), Zurbano-Berenguer y García-Gordillo (2017).

Específicamente, y en cuanto al contenido de los protocolos, existen trabajos que analizan las recomendaciones para establecer semejanzas y diferencias y, en la mayoría de los casos, llegan a una misma conclusión: existe una gran homoge-

2 IPV (intimate partner violence) es como se refiere la literatura internacional a la violencia afectiva entre las parejas.

3 Es una traducción libre del original. 
neidad en las recomendaciones propuestas por los manuales. Martínez-Rodríguez (2012) resume los diez rasgos comunes recogidos en los códigos:

1. Cuáles son (o no) los términos más apropiados: violencia de género, violencia contra las mujeres, violencia machista, violencia doméstica, etc.

2. Qué es la violencia de género: problema social y estructural, un atentado contra los derechos humanos, la dignidad y la libertad de las mujeres.

3. Contextualización de los hechos: causas culturales y sociológicas. No caer en justificaciones tales como alcohol, drogas, celos o enfermedad mental.

4. No estereotipar: las VVCMM no entienden de etnia, cultura, nivel educativo ni económico; se dan en todas las clases sociales.

5. Consideración de lacra social y no de suceso aislado y fortuito.

6. No emplear recursos sensacionalistas para cubrir periodísticamente las VVCMM.

7. Ofrecer un seguimiento de las noticias, especialmente de aquellas donde las mujeres logran salir del infierno de la violencia.

8. Ofrecer información de servicio que sea útil para las mujeres víctimas.

9. Mantener el anonimato de la víctima y respetar la presunción de inocencia del maltratador y/o asesino.

10. Utilización de fuentes expertas, no recurrir a familiares, vecindario y amistades.

En lo referido al seguimiento de las recomendaciones, la literatura académica coincide en reconocer una mejora en los encuadres -se ha pasado de un encuadre puramente episódico a uno más temático- (Carballido, 2009), en las terminologías -apenas se emplean términos denostados como violencia doméstica- y también en la cobertura, ya que las VVCMM han sufrido un proceso de tematización, es decir, se han convertido en un asunto prácticamente imprescindible en las agendas mediáticas, lo que supone, por un lado, un aumento cuantitativo de su presencia en los medios ganando visibilidad y, por otro, una mejora cualitativa en la forma de abordar periodísticamente el fenómeno (Soriano, 2004; Vega, 2014).

En la actualidad, sin embargo, el debate se centra en si, a pesar de la mejora cualitativa, el tratamiento informativo de esta realidad cumple los estándares de calidad ético-periodísticos recogidos en los códigos y si la publicación de las noticias perjudica o beneficia tanto a las víctimas y supervivientes de esta lacra-revictimizándolas y culpabilizándolas o dignificándolas y empoderándolas- como a la comprensión social del problema por parte de la ciudadanía.

La realidad periodística parece confirmar que la abundancia de materiales deontológicos sobre VVCMM no se corresponde de manera proporcional a su implementación por parte de los profesionales. Es más, según algunas autoras se "siguen cometiendo los mismos errores regulados en los numerosos decálogos de buenas prácticas" (Jorge, De la Maya y García, 2016: 996), ya que estas guías presentan una serie de restricciones como su "carácter voluntario" y su "limitado alcance y difusión" (Gallego, 2003: 233).

A estas limitaciones se añaden otras que hacen que el impacto de tales documentos sea más bien insuficiente y que van desde la "excesiva ambigüedad con la que se redactan muchas de estas normas" hasta su ya citado "escaso poder vinculante" (Soriano, 2004: 168). En cuanto a la poca concreción en su redacción, esta no facilita su aplicación por parte de los 
profesionales debido a la urgencia y rapidez con las que trabajan -no resultan útiles ni fáciles-, y su carácter voluntario, propio de la autorregulación, traslada su efectividad al libre compromiso -que variará en función del conocimiento y de la sensibilidad hacia las VVCMM- de los periodistas.

Para Aznar, los profesionales de la comunicación son:

"el sujeto cualificado encargado de la realización de los medios, una cualificación oportunamente avalada mediante la preparación y formación correspondientes. Son ellos quienes están especialmente obligados a conocer los aspectos valorativos y normativos de la actividad comunicativa, así como también a tener una especial sensibilidad acerca de los efectos derivados de su actividad [...] el profesional es quien está llamado a incorporar, a través de su labor cualificada, los aspectos normativos de la comunicación. Los aspectos éticos de la comunicación deben entrar en el proceso productivo de los medios gracias a los periodistas" (2005b: 59-60).

Sin embargo, estudios que analizan la distancia entre las recomendaciones y su aplicación en el ejercicio del periodismo señalan tanto la falta de formación académica y profesional específica en el tema como la falta de conocimiento de los documentos deontológicos por parte del colectivo de periodistas como causas principales para su incumplimiento (Martínez-Rodríguez, 2011; Zurbano-Berenguer, 2015b). Pero, además, y aun teniendo conocimiento de dichas pautas, si los profesionales dudan de su eficacia, si no se esfuerzan por ponerlas en práctica (Aznar, 2005b) o ven esta ingente producción deontológica como un intento de controlar su actividad y limitar su libertad profesional, simplemente las rechazarán.

Coincidiendo con Zurbano-Berenguer, parece "prioritario consensuar las estrategias de acción con quienes han de desempeñarlas" (2015b: 345), en vez de seguir con la profusa publicación de manuales de buenas prácticas que, además, no hacen sino repetir el contenido deontológico ya existente. Porque, como subraya Aznar, "la mejor garantía para que un código no limite las diferentes formas de entender el periodismo y la comunicación es que en su redacción y aprobación participe el mayor número posible de profesionales, siendo fruto del debate y el consenso de todos" (2005a: 61).

En relación al origen y procedencia de estos protocolos sobre VVCMM, algunas investigaciones ya han realizado taxonomías y profundizaciones (Martínez-Rodríguez, 2011; Zurbano-Berenguer, 2015b; Edo, 2017), aunque la mayoría coincide en señalar cuatro tipos de autorías:

- Poderes públicos: gobiernos locales y autonómicos y sus consejerías e Institutos de la Mujer. Dos de los documentos que pueden asociarse a este tipo de autoría son Las noticias sobre violencia contra las mujeres. Trátalas bien, 2000, del Ayuntamiento de Pamplona o Pautas para el tratamiento informativo adecuado de la violencia contra la mujer en los medios de comunicación, 2011, del Ministerio de la Mujer y Desarrollo Social de Perú.

- Organizaciones profesionales: asociaciones de la prensa, colegios de periodistas, la Federación de Asociaciones de Periodistas de España (FAPE) o la Federación Internacional de Periodistas (FIP). En este apartado es importante destacar la iniciativa de las asociaciones de mujeres periodistas, como la catalana o granadina, para la elaboración y publicación de dichos manuales: Decálogo sobre el tratamiento informativo de la violencia de género en los medios de comunicación, 2005, de la Agrupación de Mujeres Periodistas de la Asociación de la Prensa de Granada y Decálogo de buenos usos en la información sobre violencia doméstica, 2007, de la Red Internacional de Mujeres Periodistas y Comunicadoras de Cataluña. 
- Sociedad civil: como en el caso anterior, se trata, en su mayoría, de organizaciones femeninas como la Federación de Mujeres Progresistas o el Club de las 25 quien en 2007 publica Propuesta de decálogo para el tratamiento de la violencia de género en los medios de comunicación. Siguiendo a Aznar, dichos documentos "reflejan este compromiso creciente de algunos ciudadanos por mejorar los medios" (2005b: 26).

- Medios de comunicación: aun siendo los más escasos, suponen el mayor nivel de compromiso por parte de quienes los elaboran y publican, los periodistas. El primer documento en España de estas características será el Decálogo para informar sobre violencia de género, 2008, del diario Público.

Esta procedencia heterogénea y colaborativa de los códigos la destaca Martínez-Rodríguez al señalar que:

“Una de las particularidades más reseñable y positiva es que, pese a tratarse de normativas deontológicas, que afectan a colectivos profesionales, su iniciativa procede en varios casos de la cooperación de éstos con diferentes administraciones que intentan velar por el mismo fin: acabar con la violencia ejercida contra las mujeres por todos los medios a su alcance" (2012: 66).

Así pues, esta cooperación permite que existan documentos mixtos que, además, son considerados hitos en la historia de los medios de comunicación y la lucha contra las VVCMM. Ejemplo de ello es el convenio de colaboración firmado en 2001 por el Instituto Oficial de Radio y Televisión (IORTV) y el Instituto de la Mujer y que supondrá la apertura a "la vía de incorporación de este tema [VVCMM] en los códigos y prácticas de autorregulación” (Carballido, 2007: 234). Un convenio que culminará en el I Foro Nacional “Mujer, violencia y medios de comunicación”, celebrado en 2002, y del que surgirá el Manual de Urgencia, una completa guía para el tratamiento de las VVCMM y que ratificarán voluntariamente y a posteriori más medios de comunicación (López, 2006).

Esta profusa producción de recomendaciones plantea un panorama positivo en tanto que cataliza esfuerzos sostenidos y diversos. Sin embargo, presenta el siguiente inconveniente: que esa preocupación de los diferentes sectores sociales en torno al fenómeno puede responder, en ocasiones, más a la autoexigencia de manifestar su posición pública en contra de las VVCMM que a la verdadera concienciación social y preocupación por el cómo los medios informan sobre la problemática y la influencia, cuanto menos negativa, que puedan estar ejerciendo sobre la opinión pública. Por lo que los esfuerzos se quedan en el plano de lo discursivo restándole eficacia a estos protocolos.

Y así lo manifiesta Zurbano-Berenguer al explicar que esta multiplicación de documentos "parece limitarse a la necesidad [de quienes los publican] de evidenciar públicamente la adhesión a las políticas de igualdad de género [...] y que parecen orientados más a la publicidad institucional que a su implementación efectiva por parte de los y las periodistas" (2015b: 344-345).

A los actuales estudios sobre deontología periodística y VVCMM parece, pues, necesario sumarles una reflexión complementaria: zinfluyen los sesgos de género en la elaboración de los materiales?

Tomando como punto de partida la 'hipótesis de la feminización del periodismo' de Van Zoonen -según la cual un incremento de las mujeres en las redacciones supondría un cambio en la estructura sociodemográfica del colectivo de periodistas y, consecuentemente, un cambio en la práctica y en los contenidos periodísticos- (cit. en De-Miguel et al., 2017) para contextualizarla en el plano de la producción deontológica monográfica, cabe preguntarse: ¿están las mujeres, por 
el mero hecho de ser mujeres, más preocupadas que los hombres por el tratamiento informativo de las violencias que sufren a diario? Y es la respuesta a esta pregunta donde se encuentra la articulación entre la hipótesis de la feminización del periodismo y la que sostenemos las autoras de este estudio sobre la feminización del trabajo deontológico específico en materia de VVCMM.

Las posturas frente a esta hipótesis son diversas. Hay quienes sostienen que las mujeres periodistas no muestran una mayor predisposición a incluir temas de interés femenino, a introducir la perspectiva de género en los contenidos mediáticos o a tratar con mayor amplitud las cuestiones del género y de la desigualdad de lo que lo harían los periodistas varones (Gallego, 2002). Mientras que otros entienden la feminización de la profesión periodística tanto en términos cuantitativos como cualitativos. En concreto, Limor y Lavie (cit. en Soriano, Cantón y Díez, 2005) distinguen dos posiciones: la que vincula la transformación cuantitativa con un cambio en el tratamiento de la información y la que no considera que un incremento de mujeres en la profesión vaya a activar la modificación de los contenidos periodísticos, ya que estos se rigen por los valores noticiosos en los que se excluye la categoría de género.

A nivel internacional, los estudios que analizan el tipo de periodismo ejercido por mujeres, y su diferencia con el ejercido por hombres, observan que las mujeres y las minorías étnicas tienen más probabilidades de convertirse en fuente informativa cuando son ellas las que escriben las noticias (Rodgers y Thorson, 2003). También, cuando son ellas las que copan la dirección de un medio, sus reporteros y reporteras tienden a buscar e incluir más fuentes femeninas en las informaciones que cuando el medio está dirigido por hombres (Everbach, 2006).

Y en el ámbito español se repite la situación. Por un lado, los informes llevados a cabo en España por el Proyecto Global de Monitorización de los Medios -conocido como GMMP por sus siglas en inglés- ${ }^{4}$ corroboran que el género del periodista influye en la selección del sujeto de la noticia: en las noticias elaboradas por mujeres periodistas se observa mayor presencia del sujeto femenino que en las elaboradas por hombres (GMMP, 2015). Por otro, la investigación desarrollada por Matud, Rodríguez y Espinosa (2011) en la prensa española encontró que el número de artículos escritos por hombres duplicaba al número de escritos por mujeres y que en aquellos artículos donde se consultaron fuentes, estas fueron en su mayoría voces masculinas.

Respecto al problema específico de las VVCMM, en 2010, la encuesta llevada a cabo por Martínez-Sánchez a un total de 945 profesionales de los medios de comunicación españoles -40\% hombres y $60 \%$ mujeres- ponía de manifiesto la diferente percepción entre las y los periodistas respecto al tratamiento informativo del fenómeno. Algunos de los resultados fueron:

- "El 53,12\% de los hombres considera lo más noticioso la agresión de una mujer a un hombre mientras que el 50,18\% de las mujeres considera lo más noticioso una sentencia condenatoria para un agresor de mujeres.

- El 50,42\% de los hombres cree que en las noticias deben aparecer descripciones del modus operandi y los detalles de los crímenes; entre las mujeres lo creen así el 33,27\%" (2010: 27).

En síntesis, son estas reflexiones sobre el posible vínculo entre la presencia de mujeres en los medios y su forma 'diferenciada' de ejercer la profesión las que nos llevan a plantear si existe una mayor presencia de mujeres en la elaboración de

4 Es una iniciativa a nivel mundial que investiga, mediante el monitoreo, la incidencia y la representación del género en los medios de comunicación. Sus inicios se remontan a 1995 y cada cinco años documenta los cambios producidos en la representación de las mujeres en las noticias de todo el mundo. 
los códigos deontológicos sobre VVCMM y si la distribución de los sexos participantes en los manuales es un elemento decisivo en el resultado final de estos. De tal modo que, la hipótesis de la feminización del periodismo trasladada al plano de la deontología supone preguntarse: ¿existe una mayor preocupación y sensibilidad de las mujeres por este problema en el campo periodístico?, ¿̇hay una mayor participación de las mujeres en la elaboración de estos documentos? y ¿qué implicaciones tiene la diferencia de participación entre hombres y mujeres en los códigos?

\section{Hipótesis y objetivos}

Por todo lo expuesto hasta ahora, la presente investigación parte de la hipótesis de que las mujeres dedicadas al estudio -académicas e investigadoras- y a la práctica de la comunicación -profesionales de los medios-, o al ámbito genérico de la mujer y la igualdad -psicólogas, trabajadoras sociales, abogadas, etc.- están más concienciadas y sensibilizadas con la información que afecta a las mujeres -siendo las VVCMM uno de los temas que mayor preocupación suscita- participando por ello en mayor proporción que los hombres en la elaboración de los códigos deontológicos sobre VVCMM y medios de comunicación.

Mientras que los objetivos que persigue este trabajo son:

1. Identificar la autoría específica de quienes han asesorado y/o redactado las recomendaciones atribuidas a instituciones públicas, privadas y académicas, medios, asociaciones de prensa, colectivos sociales, etc.

2. Desagregar y cuantificar la participación de mujeres y de hombres específicamente y evaluar su proporcionalidad.

3. Evaluar la autoría específica de los documentos deontológicos con el nivel de compromiso de dichos documentos.

\section{Objeto de estudio y método}

Este trabajo presenta una muestra de 58 códigos sobre VVCMM y medios de comunicación, publicados en España ${ }^{5}$ en diferentes países de América Latina desde 1999 hasta 2018 (ver cuadro 1).

La recopilación se ha realizado mediante la revisión bibliográfica específica en el tema, tanto académica como profesional -como es el caso de los propios manuales que hacen referencia a otros códigos-, ya que la revisión de literatura es una técnica metodológica más, e incluso "un paso obligado en la investigación social en general", para llevar a cabo estudios e investigaciones, sean de corte cualitativo o cuantitativo (Valles, 1999: 109). Del mismo modo, las nuevas tecnologías, que permiten estar en contacto directo con Institutos de la Mujer, asociaciones de prensa, colectivos feministas y organismos públicos, han facilitado, corroborado y ampliado este compendio.

Quepa destacar dos cuestiones: que la muestra no es representativa, aunque haya tenido en su definición aspiraciones de exhaustividad y que, por ende, los resultados no son representativos, aunque sí fieles a una realidad bien documentada; y

5 También se ha incluido el Protocolo de la Federación Internacional de Periodistas (2008) porque, a pesar de no pertenecer únicamente al contexto español, entre sus miembros se encuentran destacadas asociaciones de periodistas y sindicatos españoles como la FAPE, FeSP, CCOO y ELA (Euskal Sindikatua). 
Deontología periodística en materia de violencias contra las mujeres ¿Quién elabora los documentos?...

que los documentos extraídos de la esfera latinoamericana -los más divulgados y accesibles- sirven únicamente a modo de ejemplo en otras coordenadas geo-políticas y de ningún modo se pretende representar al conjunto de países que la integran.

Cuadro 1. Documentos deontológicos, españoles y latinoamericanos, sobre violencias contra las mujeres y medios de comunicación

\begin{tabular}{|c|c|c|c|c|}
\hline Ref. & Año & Título & Autoría & Dónde \\
\hline 1 & 1999 & $\begin{array}{l}\text { Decálogo de recomendaciones a los medios de } \\
\text { comunicación para el tratamiento de la violencia } \\
\text { contra las mujeres. Cómo tratar bien los malos tratos }\end{array}$ & Instituto Andaluz de la Mujer & Andalucía \\
\hline 2 & 2000 & $\begin{array}{l}\text { Decálogo para los medios de comunicación sobre el } \\
\text { tratamiento de la violencia contra las mujeres }\end{array}$ & $\begin{array}{l}\text { Ayto. de Pamplona, Universidad de } \\
\text { Navarra y Fundación IPES }\end{array}$ & Navarra \\
\hline 3 & 2001 & $\begin{array}{l}\text { Manual de estilo periodístico para informaciones } \\
\text { sobre casos de violencia doméstica o que afecten a } \\
\text { menores }\end{array}$ & $\begin{array}{l}\text { Medios de comunicación de la } \\
\text { Demarcación de Girona }\end{array}$ & Cataluña \\
\hline 4 & 2002 & $\begin{array}{l}\text { Manual de urgencia sobre el tratamiento informativo } \\
\text { de la violencia contra las mujeres }\end{array}$ & IORTV e Instituto de la Mujer & España \\
\hline 5 & 2002 & $\begin{array}{l}\text { Notícies amb llaç blanc. Manual per a periodistes } \\
\text { sobre la violència domèstica }\end{array}$ & Unió de Periodistes Valencians & C. Valenciana \\
\hline 6 & 2003 & $\begin{array}{l}\text { Recomendaciones sobre el tratamiento de la } \\
\text { violencia contra las mujeres en los medios de } \\
\text { difusión }\end{array}$ & Instituto Navarro de la Mujer & Navarra \\
\hline 7 & 2003 & $\begin{array}{l}\text { Protocolo para el tratamiento informativo de la } \\
\text { violencia de género y agresiones sexuales en La Rioja }\end{array}$ & Gobierno de La Rioja & La Rioja \\
\hline 8 & 2003 & $\begin{array}{l}\text { Decálogo para el tratamiento informativo de los } \\
\text { malos tratos en el entorno familiar }\end{array}$ & $\begin{array}{l}\text { Instituto Balear de la Mujer, Sindicato } \\
\text { de Periodistas de las Islas Baleares y } \\
\text { Gobierno de las Islas Baleares }\end{array}$ & Islas Baleares \\
\hline 9 & 2004 & $\begin{array}{l}\text { Recomanacions del Consell de l'Audiovisual de } \\
\text { Catalunya sobre el tractament de la violència de } \\
\text { gènere als programes informatius i d'entreteniment } \\
\text { als mitjans de comunicació }\end{array}$ & $\begin{array}{l}\text { Consell de l'Audiovisual de Catalunya } \\
\text { (CAC) }\end{array}$ & Cataluña \\
\hline 10 & 2004 & $\begin{array}{l}\text { Medios de comunicación e violencia de xénero. } \\
\text { Declaración de Compostela }\end{array}$ & $\begin{array}{l}\text { Observatorio Galego dos Medios y } \\
\text { Colexio Profesional de Xornalistas de } \\
\text { Galicia }\end{array}$ & Galicia \\
\hline 11 & 2004 & $\begin{array}{l}\text { Decálogo básico (Decálogo de Zaragoza) para iniciar } \\
\text { el debate en los medios de comunicación }\end{array}$ & Ayto. de Zaragoza & Aragón \\
\hline 13 & 2005 & $\begin{array}{l}\text { Decálogo sobre el tratamiento informativo de la } \\
\text { violencia de género en los medios de comunicación }\end{array}$ & $\begin{array}{l}\text { Agrupación de Mujeres Periodistas de la } \\
\text { Asociación de la Prensa de Granada }\end{array}$ & Andalucía \\
\hline
\end{tabular}




\begin{tabular}{|c|c|c|c|c|}
\hline 14 & 2005 & $\begin{array}{l}\text { Decálogo - Recomendaciones para evitar una } \\
\text { comunicación sexista y androcéntrica y para el } \\
\text { tratamiento adecuado de la violencia de género }\end{array}$ & Consejo Comarcal de El Bierzo & Castilla y León \\
\hline 15 & 2005 & $\begin{array}{l}\text { Las noticias de los malos tratos. Propuestas para } \\
\text { abordar la información sobre la violencia de género }\end{array}$ & Instituto Aragonés de la Mujer & Aragón \\
\hline 16 & 2005 & $\begin{array}{l}\text { Lenguaje no sexista en medios de comunicación y } \\
\text { publicidad. Apuntes para la igualdad }\end{array}$ & Cabildo de Tenerife & Canarias \\
\hline 17 & 2006 & $\begin{array}{l}\text { Código para el tratamiento informativo de la } \\
\text { violencia de género }\end{array}$ & Junta de Castilla y León & Castilla y León \\
\hline 18 & 2007 & $\begin{array}{l}\text { Propuesta de decálogo para el tratamiento de la } \\
\text { violencia de género en los medios de comunicación }\end{array}$ & El Club de las 25 & España \\
\hline 19 & 2007 & $\begin{array}{l}\text { Protocolo de actuación periodística y publicitaria } \\
\text { sobre igualdad de oportunidades entre mujeres y } \\
\text { hombres y tratamiento informativo sobre la violencia } \\
\text { de género }\end{array}$ & Gobierno de Cantabria & Cantabria \\
\hline 20 & 2007 & $\begin{array}{l}\text { Medios de comunicación e violencia de xénero. } \\
\text { Manual de Redacción Xornalística }\end{array}$ & Xunta de Galicia & Galicia \\
\hline 21 & 2007 & $\begin{array}{l}\text { Decálogo de buenos usos en la información sobre } \\
\text { violencia doméstica }\end{array}$ & $\begin{array}{l}\text { Red Internacional de Mujeres } \\
\text { Periodistas y Comunicadoras de } \\
\text { Cataluña }\end{array}$ & Cataluña \\
\hline 22 & 2008 & Decálogo para informar sobre violencia de género & Público & España \\
\hline 23 & 2008 & $\begin{array}{l}\text { La igualdad de género no es cuestión de suerte: } \\
\text { Catálogo de recomendaciones para el tratamiento } \\
\text { de la violencia de género en los medios de } \\
\text { comunicación }\end{array}$ & Cabildo de Tenerife & Canarias \\
\hline 24 & 2008 & $\begin{array}{l}\text { Recomendaciones para un tratamiento informativo } \\
\text { adecuado de la violencia contra la mujer en los } \\
\text { medios de comunicación }\end{array}$ & $\begin{array}{l}\text { I Congreso Internacional Mujer y } \\
\text { Medios de Comunicación (CIMMCO) }\end{array}$ & C. Valenciana \\
\hline 25 & 2008 & $\begin{array}{l}\text { Protocolo de la FIP para la cobertura informativa de } \\
\text { casos de violencia contra las mujeres }\end{array}$ & $\begin{array}{l}\text { Federación Internacional de Periodistas } \\
\text { (FIP) }\end{array}$ & España \\
\hline 26 & 2009 & $\begin{array}{l}\text { Recomendaciones: El tratamiento de la violencia } \\
\text { machista en los medios de comunicación }\end{array}$ & $\begin{array}{l}\text { Consell de l'Audiovisual de Catalunya } \\
\text { (CAC) }\end{array}$ & Cataluña \\
\hline 27 & 2009 & $\begin{array}{l}\text { Los periodistas nos comprometemos. Manifiesto } \\
\text { contra la violencia de género }\end{array}$ & Asociación de la Prensa de La Rioja & La Rioja \\
\hline 28 & 2010 & $\begin{array}{l}\text { Recomendaciones genéricas de cómo informar sobre } \\
\text { violencia contra la mujer en las relaciones de pareja }\end{array}$ & Centro Reina Sofía & España \\
\hline 29 & 2010 & Intervención en publicidad y comunicación sexista & Instituto Canario de Igualdad & Canarias \\
\hline 30 & 2010 & $\begin{array}{l}\text { Código de los profesionales de CSTV para la } \\
\text { elaboración de informaciones sobre violencia } \\
\text { machista }\end{array}$ & Canal Sur Televisión & Andalucía \\
\hline
\end{tabular}


Deontología periodística en materia de violencias contra las mujeres ¿Quién elabora los documentos?...

\begin{tabular}{|c|c|c|c|c|}
\hline 31 & 2011 & $\begin{array}{l}\text { Recomendaciones: Tratamiento informativo para la } \\
\text { igualdad de género en Extremadura }\end{array}$ & $\begin{array}{l}\text { Instituto de la Mujer de Extremadura, } \\
\text { Asociaciones de la Prensa de Mérida, } \\
\text { Cáceres y Badajoz y medios de } \\
\text { comunicación regionales extremeños }\end{array}$ & Extremadura \\
\hline 32 & 2011 & $\begin{array}{l}\text { Diez pautas para un tratamiento eficaz de la } \\
\text { violencia de género }\end{array}$ & Elena Bandrés Goldáraz & España \\
\hline 33 & 2013 & $\begin{array}{l}\text { Derecho a la Información y Justicia: Guía para el } \\
\text { tratamiento informativo de los procesos judiciales }\end{array}$ & $\begin{array}{l}\text { Consejo Audiovisual de Andalucía } \\
\text { (CAA) }\end{array}$ & Andalucía \\
\hline 34 & 2014 & $\begin{array}{l}\text { Informar sobre la violencia contra las mujeres. } \\
\text { Guías de buenas prácticas para los medios de } \\
\text { comunicación }\end{array}$ & Ayto. de Zaragoza & Aragón \\
\hline 35 & 2015 & $\begin{array}{l}\text { Decálogo - El papel garantista del Consejo } \\
\text { Audiovisual de Andalucía del tratamiento } \\
\text { informativo ético de la violencia machista en los } \\
\text { medios }\end{array}$ & Ana Jorge Alonso & España \\
\hline 36 & 2015 & $\begin{array}{l}\text { Propuestas de la jornada "Tratamiento informativo } \\
\text { de la violencia machista en la era digital" }\end{array}$ & $\begin{array}{l}\text { Participantes de la jornada organizada } \\
\text { por La marea }\end{array}$ & Madrid \\
\hline 37 & 2016 & $\begin{array}{l}\text { Guía para el tratamiento informativo de la violencia } \\
\text { de género }\end{array}$ & $\begin{array}{l}\text { Consejo Audiovisual de Andalucía } \\
\text { (CAA) }\end{array}$ & Andalucía \\
\hline 38 & 2016 & $\begin{array}{l}\text { Protocolo de buenas prácticas: Tratamiento de la } \\
\text { información sobre violencia machista en los medios } \\
\text { de comunicación }\end{array}$ & $\begin{array}{l}\text { Asociación de Periodistas de Aragón y } \\
\text { Ayto. de Zaragoza }\end{array}$ & Aragón \\
\hline 39 & 2016 & $\begin{array}{l}\text { Decálogo para el tratamiento informativo de la } \\
\text { violencia contra las mujeres }\end{array}$ & $\begin{array}{l}\text { BEGIRA (Comisión Asesora para un } \\
\text { uso no sexista de la publicidad y la } \\
\text { comunicación) } \\
\text { EMAKUNDE (Instituto Vasco de la } \\
\text { Mujer) }\end{array}$ & País Vasco \\
\hline 40 & 2017 & Periodismo contra las violencias machistas & La marea y Oxfam Intermón & España \\
\hline 41 & 2017 & $\begin{array}{l}\text { Guía para el tratamiento informativo de la violencia } \\
\text { de género }\end{array}$ & Junta de Castilla y León & Castilla y León \\
\hline 42 & 2018 & $\begin{array}{l}\text { Decálogo para el tratamiento periodístico de las } \\
\text { víctimas de la violencia machista }\end{array}$ & $\begin{array}{l}\text { Asociación de Periodistas por la } \\
\text { Igualdad }\end{array}$ & Aragón \\
\hline 43 & 2018 & $\begin{array}{l}\text { Manual d'estil per al tractament de la violència } \\
\text { masclista i el llenguatge inclusiu en els mitjans de } \\
\text { comunicació }\end{array}$ & Unió de Periodistes Valencians & C. Valenciana \\
\hline 44 & 2007 & $\begin{array}{l}\text { La violencia hacia las mujeres en los medios de } \\
\text { comunicación. Transformando las noticias }\end{array}$ & $\begin{array}{l}\text { CISCSA y Red Mujer y Hábitat de } \\
\text { América Latina }\end{array}$ & Argentina \\
\hline 45 & 2008 & $\begin{array}{l}\text { Decálogo para el tratamiento periodístico de la } \\
\text { violencia contra las mujeres }\end{array}$ & $\begin{array}{l}\text { PAR (Periodistas de Argentina en Red } \\
\text { por una comunicación no sexista) }\end{array}$ & Argentina \\
\hline
\end{tabular}




\begin{tabular}{|c|c|c|c|c|}
\hline 46 & 2008 & $\begin{array}{l}\text { Lentes lilas para los medios de comunicación. La } \\
\text { construcción de las noticias sobre violencia hacia las } \\
\text { mujeres }\end{array}$ & $\begin{array}{l}\text { UNFPA y Secretaría de la Mujer } \\
\text { Presidencia de la República del } \\
\text { Paraguay }\end{array}$ & Paraguay \\
\hline 47 & 2009 & $\begin{array}{l}\text { Manual de género para periodistas: } \\
\text { recomendaciones básicas para el ejercicio del } \\
\text { periodismo con enfoque de género }\end{array}$ & $\begin{array}{l}\text { América Latina Genera (Área Práctica } \\
\text { de Género RSCLAC PNUD) }\end{array}$ & América Latina \\
\hline 48 & 2009 & $\begin{array}{l}\text { Noticias que salvan vidas. Manual periodístico para } \\
\text { el abordaje de la violencia contra las mujeres }\end{array}$ & $\begin{array}{l}\text { Amnistía Internacional Argentina- } \\
\text { Asociación Civil Pro Amnistía }\end{array}$ & Argentina \\
\hline 49 & 2010 & $\begin{array}{l}\text { Por un periodismo no sexista. Pautas para comunicar } \\
\text { desde una perspectiva de género en Chile }\end{array}$ & OREALC/UNESCO Santiago & Chile \\
\hline 50 & 2011 & $\begin{array}{l}\text { La violencia tiene mil caras. Guía para Profesionales } \\
\text { y Comunicadores/as de Medios de Comunicación en } \\
\text { Violencia contra las Mujeres }\end{array}$ & UNFPA & Chile \\
\hline 51 & 2011 & $\begin{array}{l}\text { Pautas para el tratamiento informativo adecuado } \\
\text { de la violencia contra la mujer en los medios de } \\
\text { comunicación }\end{array}$ & $\begin{array}{l}\text { Ministerio de la Mujer y Desarrollo } \\
\text { Social }\end{array}$ & Perú \\
\hline 52 & 2011 & $\begin{array}{l}\text { Proyecto de ley para el tratamiento mediático de la } \\
\text { violencia de género }\end{array}$ & Gustavo Ferrari & Argentina \\
\hline 53 & 2011 & $\begin{array}{l}\text { Manual para periodistas y comunicadores sobre el } \\
\text { tratamiento de noticias de violencia familiar }\end{array}$ & $\begin{array}{l}\text { Acción por los Niños y Centro de } \\
\text { Capacitación J.M. Arguedianos }\end{array}$ & Perú \\
\hline 54 & 2014 & $\begin{array}{l}\text { Violencias puertas adentro. Guía para una cobertura } \\
\text { periodística con enfoque de género y generaciones }\end{array}$ & $\begin{array}{l}\text { Consejo Nacional Consultivo de Lucha } \\
\text { contra la Violencia Doméstica y Sistema } \\
\text { Integral de Protección a la Infancia y } \\
\text { Adolescencia contra la Violencia }\end{array}$ & Uruguay \\
\hline 55 & 2014 & $\begin{array}{l}\text { ¿Los periodistas podemos ayudar? Manual para } \\
\text { periodistas que informan sobre violencia de género }\end{array}$ & Conexión - Fondo de emancipación & Bolivia \\
\hline 56 & 2015 & $\begin{array}{l}\text { Periodismo libre de violencia. Protocolo para el } \\
\text { abordaje informativo de la violencia contra las } \\
\text { mujeres basada en género }\end{array}$ & $\begin{array}{l}\text { Ministerio de Comunicación del Estado } \\
\text { Plurinacional de Bolivia }\end{array}$ & Bolivia \\
\hline 57 & 2016 & $\begin{array}{l}\text { Guía para el tratamiento mediático responsable de } \\
\text { casos de violencia contra las mujeres }\end{array}$ & $\begin{array}{l}\text { Defensoría del Público de Servicios de } \\
\text { Comunicación Audiovisual }\end{array}$ & Argentina \\
\hline 58 & 2017 & $\begin{array}{l}\text { ¿Cómo abordar noticias de violencia contra las } \\
\text { mujeres? }\end{array}$ & $\begin{array}{l}\text { Ministerio de la Mujer y Poblaciones } \\
\text { Vulnerables }\end{array}$ & Perú \\
\hline
\end{tabular}

Fuente: Elaboración propia

Para identificar la autoría y cuantificar la participación de mujeres y hombres en la elaboración de los códigos -objetivos 1 y 2-, se ha contactado, telefónicamente o a través de correo electrónico, con las instituciones y entidades firmantes cuando el propio documento no lo indicaba. En alguna ocasión, las respuestas, bien por protección de datos o por desconocimiento, no han arrojado luz sobre la autoría, en cuyo caso se ha tenido en cuenta quiénes -mujeres u hombres- han suscrito los manuales a título personal o en representación de sus organismos, empresas o medios de comunicación. Cuando ello tampoco ha sido posible, la autoría se ha atribuido a presuntamente mujeres, por ser instituciones formadas en su mayoría 
Deontología periodística en materia de violencias contra las mujeres ¿Quién elabora los documentos?...

por mujeres quienes editan el documento -como son los Institutos de la Mujer o los colectivos de mujeres periodistas-, o, directamente, a las organizaciones que aparecen como autoras.

Así pues, se han establecido cinco tipos de autorías en el asesoramiento y/o redacción de los manuales:

a) Han participado solo mujeres o mayoría de mujeres

b) Han participado solo hombres o mayoría de hombres

c) Han participado un número equitativo de hombres y mujeres

d) Se presupone que han participado mujeres al tratarse de Institutos de la Mujer y asociaciones de mujeres periodistas

e) Se desconoce la autoría específica y se atribuye a las entidades firmantes -autoría institucional-.

En relación al objetivo 3, evaluar las posibles diferencias en el grado de compromiso de los manuales atendiendo al género de la autoría, se ha empleado para tal medición el instrumento diseñado por Edo y Zurbano-Berenguer (2019) (cuadro 2), basado, a su vez, en las aportaciones de Aznar (2005b) y Sutherland et al. (2016). Los resultados de la investigación en la que se describe la herramienta y se aplica al mismo corpus documental que el presente trabajo con el objetivo de testar dicha herramienta aún se encuentran en proceso de impresión.

Cuadro 2. Ficha de análisis de medición del nivel de compromiso de los documentos deontológicos sobre violencias contra las mujeres

\begin{tabular}{|c|c|c|c|c|c|}
\hline \multicolumn{6}{|l|}{ IDENTIFICACIÓN } \\
\hline & Núm. referencia & \multicolumn{2}{|l|}{ Fecha } & \multicolumn{2}{|c|}{ Autoría } \\
\hline \multicolumn{6}{|c|}{ MEDICIÓN DEL COMPROMISO. INDICADORES } \\
\hline & & & Sí & No & Se desconoce \\
\hline \multicolumn{6}{|c|}{ A) Justificación científica de la propuesta } \\
\hline \multicolumn{3}{|l|}{ P1. ¿Existe una investigación previa? } & & & \\
\hline \multicolumn{6}{|l|}{ B) Aplicabilidad } \\
\hline \multicolumn{6}{|l|}{ P2. ¿Es claro, conciso y breve? } \\
\hline \multicolumn{6}{|l|}{ P3. ¿Incluye ejemplos? } \\
\hline \multicolumn{6}{|l|}{ P4. ¿Incluye nociones básicas? } \\
\hline \multicolumn{6}{|c|}{ P5. ¿Diferencia el contenido de los recursos audiovisuales? } \\
\hline \multicolumn{6}{|l|}{ C) Intencionalidad } \\
\hline \multicolumn{6}{|l|}{ P6. ¿Incluye el porqué y para qué? } \\
\hline \multicolumn{6}{|c|}{ P7. ¿Incluye estrategias de difusión e implantación entre la profesión? } \\
\hline \multicolumn{6}{|c|}{ D) Especialización y pertinencia de los autores } \\
\hline $\begin{array}{l}\text { P8. ¿Hay constancia de la colaboraci } \\
\text { género en la elaboración del docume }\end{array}$ & fesionales de la cor & nicación y/o & & & \\
\hline
\end{tabular}




\begin{tabular}{|l|l|l|l|}
\hline $\begin{array}{l}\text { P9. iHay constancia de la colaboración de investigadores de la comunicación y/o } \\
\text { género en la elaboración del documento? }\end{array}$ & & & \\
\hline TOTAL & & & \\
\hline EVALUACIÓN & N / A / O & \\
\hline
\end{tabular}

Fuente: Elaboración propia

El sistema categorial diseñado -formado por cuatro indicadores y nueve subindicadores- para la medición del nivel de compromiso de los códigos se plasma en la ficha de análisis del cuadro 2 cuyas respuestas negativa o desconocida equivale a 0 puntos y la positiva, a 1 punto. Para la evaluación, de tipo proporcional, de cada código se han establecido tres rangos diferenciados: sobre una escala de nueve puntos -correspondiente a las nueve preguntas del cuadro 2-, se considerará que el documento ofrece un grado de compromiso negativo (N) cuando no se alcancen los cinco puntos, un grado de compromiso aceptable (A) cuando el documento obtenga entre cinco y seis puntos, y óptimo (O) cuando el documento cumpla siete o más criterios.

En este trabajo se ha empleado la herramienta anterior para cruzar los datos relativos al nivel de compromiso de los manuales con el tipo de autoría de los mismos.

\section{Resultados}

En cuanto al objetivo 1, identificar la autoría específica de cada documento deontológico, el siguiente cuadro (cuadro 3) clasifica los manuales -indicados mediante las referencias atribuidas en el cuadro 1- en los cinco tipos de autorías descritos.

Cuadro 3. Autoría de los documentos deontológicos, españoles y latinoamericanos, sobre violencias contra las mujeres y medios de comunicación

\begin{tabular}{|l|l|l|}
\hline Tipos de autoría & Ref. documentos deontológicos & TOTAL \\
\hline a) Han participado solo mujeres o mayoría de mujeres & $\begin{array}{l}1,2,4,5,6,11,12,14,16,18,19,20,22,23,26,27,29, \\
32,35,36,37,40,41,42,43,44,45,46,47,48,49,50,54, \\
55,57\end{array}$ & 35 \\
\hline b) Han participado solo hombres o mayoría de hombres & $3,7,17,34,52$ & 5 \\
\hline c) Han participado un número equitativo de hombres y mujeres & $10,28,30,39,51,58$ & 6 \\
\hline $\begin{array}{l}\text { d) Se presupone que han participado mujeres al tratarse de Insti- } \\
\text { tutos de la Mujer y asociaciones de mujeres periodistas }\end{array}$ & $8,13,15,21$ & 4 \\
\hline $\begin{array}{l}\text { e) Se desconoce la autoría específica y se atribuye a las entidades } \\
\text { firmantes }\end{array}$ & $9,24,25,31,33,38,53,56$ & 8 \\
\hline
\end{tabular}

Fuente: Elaboración propia

Respecto al objetivo 2, desagregar y cuantificar la participación de mujeres y de hombres, los resultados (gráficas 1 y 2) muestran que un total de 35 códigos (60\%) han contado, en su totalidad o en mayoría, con mujeres para su elaboración y redacción -25 españoles y diez latinoamericanos- frente a cinco (9\%) cuya producción se atribuye a solo hombres o 
mayoría de ellos -cuatro españoles y uno latinoamericano-. En seis de los protocolos (10\%) han participado un número equitativo de hombres y mujeres -cuatro españoles y dos latinoamericanos-; mientras que la autoría de cuatro códigos (7\%) -todos ellos españoles- se atribuye a presuntamente mujeres por ser Institutos de la Mujer y agrupaciones de mujeres periodistas quienes firman el documento. En el resto de guías, ocho (14\%) -seis españolas y dos latinoamericanas-, se desconoce quién o quiénes las han elaborado, por lo que su autoría es institucional.

Gráfica 1. Análisis de la autoría de los documentos deontológicos, españoles y latinoamericanos, sobre violencias contra las mujeres y medios de comunicación

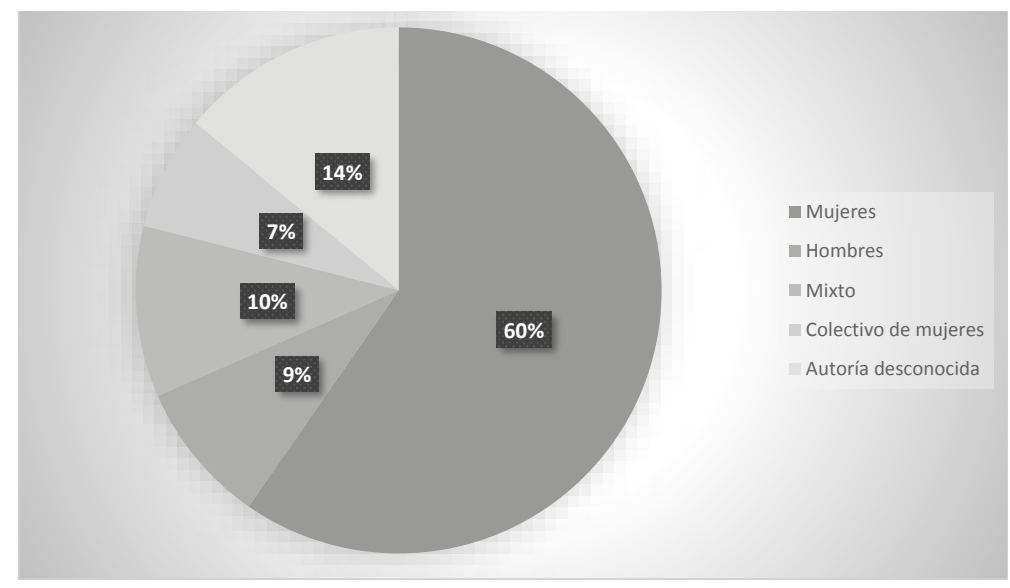

Fuente: Elaboración propia

Gráfica 2. Análisis de la autoría de los documentos deontológicos sobre violencias contra las mujeres y medios de comunicación de manera diferenciada: españoles y latinoamericanos 


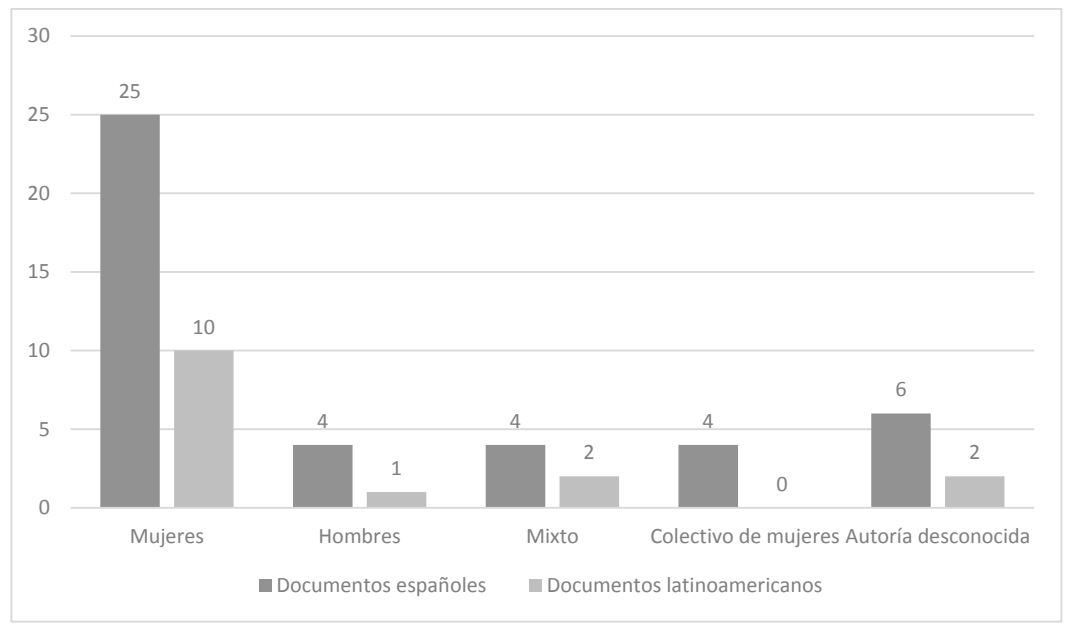

Fuente: Elaboración propia

De acuerdo al objetivo 3, evaluar la autoría específica de los documentos deontológicos en relación con el nivel de compromiso de los mismos, se ha tomado como referencia para la comparación el estudio aún inédito, y anteriormente citado, de Edo y Zurbano-Berenguer (2019). Sus resultados establecen que el 53\% de los manuales ofrece un nivel de compromiso negativo, el 38\% se situa en el rango de aceptable y el $9 \%$ presenta un nivel de compromiso óptimo. Y con respecto al presente estudio, se ha observado que las guías con un mayor nivel de compromiso son aquellas en las que intervienen mujeres o mujeres y hombres de manera equitativa, como se detalla a continuación.

Relacionando los resultados de ambos trabajos (gráfica 3), se observa que el 49\% (17) de las guías elaboradas por mujeres o mayoría de ellas suspende el nivel de compromiso, mientras que el 40\% (14) ofrece un nivel aceptable y el 11\% (4), un nivel óptimo -es decir, en el 51\% de los casos las recomendaciones elaboradas por mujeres aprueban y/o superan el nivel de compromiso-. Los protocolos atribuidos exclusiva o mayoritariamente a hombres suspenden el nivel de compromiso mínimo y obtienen en el $100 \%$ de los casos una puntuación negativa. Las guías en las que ha participado un número equitativo de mujeres y hombres, el $84 \%$ (5) de ellas aprueba el nivel de compromiso y el $16 \%$ (1) lo suspende. En cuanto a los códigos desarrollados por presuntamente mujeres, el $100 \%$ se sitúa en el rango negativo. Por último, aquellos documentos de autoría desconocida obtienen niveles de compromiso aceptable en el 37,5\% (3) de los casos, negativo en el $50 \%$ (4) y óptimo en el 12,5\% (1).

En resumen, cuando la participación es mixta o mayoritaria/exclusivamente femenina las guías resultantes obtienen en más de la mitad de las ocasiones un nivel de compromiso aceptable u óptimo. Cuando las autorías son atribuidas exclusiva o mayoritariamente a hombres y/o presuntamente a colectivos de mujeres, todos los códigos presentan un nivel de compromiso negativo. Y en el caso de las autorías desconocidas el grado de compromiso en el 50\% de las guías se suspende mientras que en el otro $50 \%$ es superado. 
Deontología periodística en materia de violencias contra las mujeres ¿Quién elabora los documentos?...

Gráfica 3. Nivel de compromiso de los documentos deontológicos españoles y latinoamericanos sobre violencias contra las mujeres clasificados por su autoría

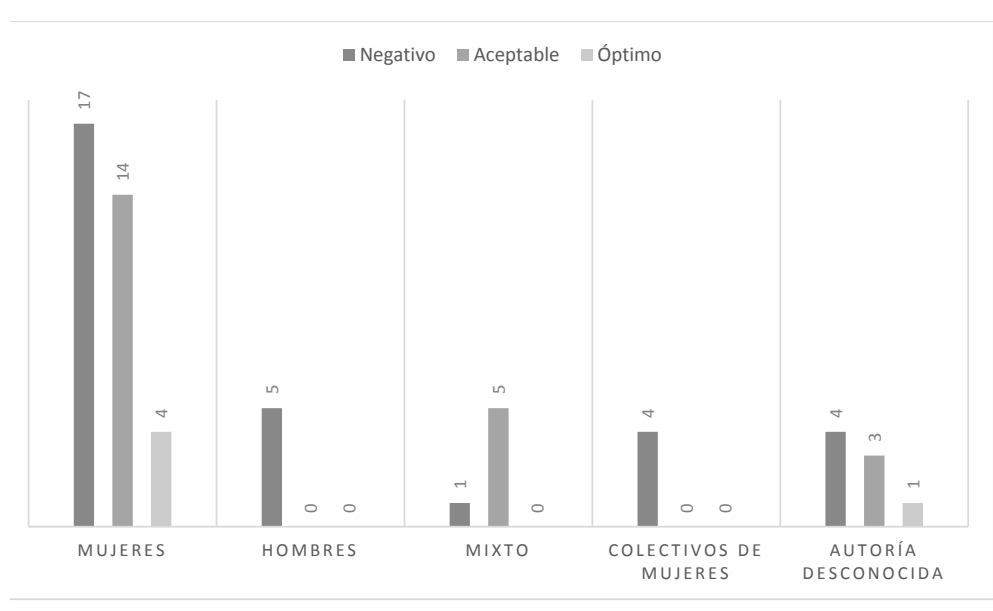

Fuente: Elaboración propia

De manera diferenciada, la autoría de los documentos españoles que obtienen un nivel de compromiso óptimo (Ref. 40, 41 y 43) corresponde a solo mujeres o mayoría de ellas. Los siete códigos que menor puntuación alcanzan (Ref. 13, 15, 18, 27, 29, 31 y 42) han sido elaborados también por mujeres o se presupone que mujeres ${ }^{6}$, a excepción de uno, cuya autoría se desconoce. Todos los códigos españoles desarrollados exclusiva o mayoritariamente por hombres (Ref. 3, 7, 17 y 34) suspenden el nivel de compromiso.

En referencia a los documentos latinoamericanos, de las dos guías con mayor puntuación (Ref. 48 y 56), una es elaborada por mujeres mientras que de la otra se desconoce su autoría. El código con menor puntuación (Ref. 55) es desarrollado por una mujer; mientras que el único documento latinoamericano elaborado por un hombre (Ref. 52) presenta un nivel de compromiso negativo.

\section{Conclusiones}

Como de los resultados se deduce, la hipótesis inicial queda ratificada demostrándose que existe una mayor presencia cuantitativa de mujeres en la elaboración de códigos y que dicha presencia afecta positivamente al grado de compromiso

6 Los códigos 18, 27, 29 y 42 están elaborados por mujeres o mayoría de ellas; los códigos 13 y 15, por una asociación de mujeres periodistas y por un Instituto regional de la Mujer, respectivamente, y del código 31 se desconoce su autoría. 
de los mismos. Es decir, las mujeres no solo participan más en la elaboración de estos documentos, sino que cualitativamente su aportación redunda en contenidos de mayor calidad y más comprometidos con la aplicabilidad de los mismos? Las principales conclusiones que pueden aportarse son:

- Que el contexto deontológico está fundamentalmente participado por mujeres.

- Que la participación de las mujeres es una garantía del compromiso de los códigos pero que los valores más altos se presentan cuando existe colaboración entre hombres y mujeres.

En relación a esta segunda conclusión, nótese que cuando participan de manera equitativa ambos sexos en la elaboración de los materiales se ofrece el porcentaje más alto de códigos que aprueban el nivel de compromiso (84\%). Lo que demuestra que la colaboración conjunta de hombres y mujeres en la elaboración de las guías se traduce en niveles de calidad, implicación y compromiso más altos, por lo que no tiene sentido seguir desaprovechando las aportaciones masculinas en cuanto a deontología periodística sobre VVCMM.

Además, este trabajo pone de manifiesto que a pesar del aumento del nivel de sensibilización que la ciudadanía tiene respecto al tema, aún queda mucho por hacer si la labor de concienciación inherente a la responsabilidad de los medios sigue recayendo mayoritariamente sobre las mujeres. Este hecho supone no solo sobrerresponsabilizar implícitamente a ellas de las medidas correctivas de este problema en el ámbito periodístico, sino también desperdiciar los esfuerzos, conocimientos, capacidades y cosmovisiones de los hombres que, todavía, parecen no haber hecho suya la lucha contra las VVCMM.

¿Por qué los manuales están participados mayoritariamente por mujeres? ¿Existe una relación espontánea entre el tema, relativo a ellas, y su participación o por el contrario existen relaciones de poder, de afinidad...? ¿Cuáles han sido las motivaciones que han llevado a las mujeres que han participado a colaborar? ¿Y a los hombres que lo han hecho? ¿Y a los que no? Estas son solo algunas de las preguntas que se abren tras el trabajo realizado. En este, sostenido sobre la hipótesis de la feminización del periodismo, se ha concluido que existe una doble feminización en la elaboración del corpus deontológico: participan más mujeres y su participación influye en el mayor grado de compromiso de los documentos elaborados. Esto, como no puede ser de otro modo, plantea cuestionamientos profundos sobre qué se entiende que deben hacer las instituciones y cómo para mejorar la calidad del periodismo -que garantiza la democracia a través de una opinión pública informada y formada- ante un problema de tal envergadura como el de las VVCMM.

Antes de finalizar quepa hacer la aclaración de que las autoras reconocen la labor de los y las profesionales del periodismo y su responsabilidad social inherente para con la sociedad y es por ello que cuestionan la utilidad, intencionalidad y elaboración de los materiales deontológicos. Muchos de los cuáles no cuentan ni con su participación ni con su conocimiento tal y como plantea Zurbano-Berenguer (2015b). Es decir, este trabajo no asume que la erradicación de las VVCMM sea una labor exclusiva del periodismo ni de los y las periodistas, pero sí que, de su labor, delimitada y consensuada bajo unos criterios deontológicos claros, depende en gran medida la sensibilidad social y la disminución progresiva de las agresiones.

$7 \quad$ En este sentido, cabe matizar que esta investigación no ha tenido en cuenta si las mujeres autoras han sido elegidas ad hoc porque se las considera las más apropiadas, preparadas y sensibilizadas para la elaboración de los documentos deontológicos aquí analizados, lo cual abre nuevas vías de investigación de corte más cualitativo. 
Por último, es importante destacar que el camino hacia la erradicación de las violencias solo puede ser transitado de la mano de medios responsables y comprometidos que contribuyan a generar marcos de sensibilidad social que rechacen las agresiones de género. Que para ello es fundamental que los documentos deontológicos no sean únicamente morales y éticos, sino que deben introducir elementos de compromiso para su comprensión, aceptación y aplicación efectiva por parte de la comunidad de profesionales del periodismo. Y que, para ello, la mejor garantía puesta de manifiesto en este trabajo es la colaboración conjunta entre mujeres y hombres.

\section{Referencias bibliográficas}

Ahmed, S. (2014). "Violence against women. Media representations of violent issues in the perspective of Pakistan", Science International, v. 26, n. 1, pp. 367-371.

Anastasio, P. A. y Costa, D. M. (2004). “Twice hurt. How newspaper coverage may reduce empathy and engender blame for female victims of crime”, Sex Roles, v. 51, n. 9-10, pp. 535-542. Doi. http.//doi.org/10.1007/s11199-004-5463-7

Aznar, H. (2005a, 2a ed. actualizada). Comunicación responsable. La autorregulación de los medios. Barcelona. Ariel.

- (2005b). Ética de la comunicación y nuevos retos sociales. Códigos y recomendaciones para los medios. Barcelona. Paidós.

Bandrés, E. (2011). "Propuesta para el tratamiento eficaz de la violencia de género", IC Revista Científica de Información y Comunicación, n. 8, pp. 113-138.

Bullock, C. F. y Cubert, J. (2002). “Coverage of Domestic Violence Fatalities by Newspapers in Washington State”, Journal of Interpersonal Violence, v. 17, n. 5, pp. 475-499. Doi. https.//doi.org/10.1177/0886260502017005001

Carballido, P. (2007). "Movimientos sociales y medios de comunicación. el cambio en el tratamiento de la violencia contra las mujeres”, Recerca, Revista de Pensament i Anàlisi, n. 7, pp. 211-240. Doi. http.//dx.doi.org/10.6035/Recerca

- (2009). "Medios de comunicación social y violencia de género. Una revisión desde la teoría del framing", en Bernardo Paniagua, J. M. et al. (eds.). Retos de la Comunicación ante la Violencia de género. Marco jurídico, discurso mediático y compromiso social. Valencia. Tirant lo Blanch, pp. 157-174.

De-Miguel, R. et al. (2017). "Women journalists in Spain. An analysis of the sociodemographic features of the gender gap", El profesional de la información, v. 26, n. 3, pp. 497-506. Doi. https.//doi.org/10.3145/epi.2017.may.16

Easteal, P.; Holland, K. y Judd, K. (2015). “Enduring themes and silences in media portrayals of violence against women”, Women's Studies International Forum, v. 48, pp. 103-113. Doi. https.//doi.org/10.1016/j.wsif.2014.10.015

Edo, A. (2017). "Estudio comparativo de los códigos deontológicos sobre violencia de género y comunicación. Bases para un manual de estilo fundamental”, en Suárez-Villegas, J.C. et al. (eds.). La desigualdad de género invisibilizada en la comunicación. Madrid: Dykinson, pp. 34-48.

Edo, A. y Zurbano-Berenguer, B. (2019). “Deontología periodística sobre violencias contra las mujeres”, El profesional de la información (trabajo pendiente de publicación). 
Everbach, T. (2006). "The Culture of a Women-Led Newspaper. An Ethnographic Study of the Sarasota Herald Tribune", Journalism \& Mass Communication Quarterly, v. 83, n. 3, pp. 477-493. Doi. https.//doi.org/10.1177/107769900608300301

Fairbairn, J. y Dawson, M. (2013). "Canadian news coverage of intimate partner homicide. Analyzing changes over time”, Feminist Criminology, v. 8, n. 3, pp. 147-176. Doi. http.//doi.org/10.1177/1557085113480824

Gallego, J. (dir.) (2002). La prensa por dentro. Producción informativa y transmisión de estereotipos de género. Barcelona. Libros de la Frontera.

- (2003). "De las recomendaciones a los mecanismos. Producción informativa y su incidencia en el tratamiento de la violencia de género", en Ramírez Alvarado, Ma ${ }^{a}$. M. (coord.). Medios de comunicación y violencia contra las mujeres. Sevilla. Instituto Andaluz de la Mujer y Fundación Audiovisual de Andalucía, pp. 228-237.

Global Media Monitoring Project (GMMP) (2015). ¿Quién figura en las noticias? Asociación Mundial para la Comunicación Cristiana (WACC). URL. http.//cdn.agilitycms.com/who-makes-the-news/Imported/reports_2015/global/gmmp_global_ report_es.pdf [Consultado el 15/06/2018].

Jorge, A.; De la Maya, R. y García, M. (2016) “Tratamiento informativo de la violencia de género en la televisión pública andaluza. Incumplimiento del código deontológico en Canal Sur", Revista Latina de Comunicación Social, n. 71, pp. 994-1006. Doi. 10.4185/RLCS-2016-1131

López, P. (2006). Representación de la violencia de género en los informativos de TVE. Madrid. IORTV e Instituto de la Mujer. - (2007). "La construcción de la Violencia de Género en los medios de comunicación”, en Congreso Abordaje Integral de la Violencia de Género Actualización. Zamora. Ayuntamiento de Zamora, pp. 34-48.

- (2008). “Los medios y la representación de género. algunas propuestas para avanzar”, Feminismo/s, v. 11, pp. 95-108. Doi. http.//dx.doi.org/10.14198/fem.2008.11.06

Lorente, M. (2009). “¿Qué papel pueden tener los medios de comunicación de masas en la erradicación de la violencia de género al amparo de la Ley Integral?”, en Bernardo Paniagua, J.M. et al. (eds.). Retos de la Comunicación ante la Violencia de género. Marco jurídico, discurso mediático y compromiso social. Valencia. Tirant lo Blanch, pp. 49-63.

Martínez-Rodríguez, B. (2010). "El tratamiento informativo de la violencia contra la mujer en Galicia hoy. un análisis a la luz de los códigos deontológicos", Observatorio (OBS) Journal, v. 4, n. 4, pp. 53-72. Doi. http.//dx.doi.org/10.15847/ obsOBS442010373

- (2011). El tratamiento de la violencia contra la mujer a la luz de los códigos deontológicos (Tesis Doctoral). Vigo. Universidad de Vigo.

- (2012). "Periodismo y responsabilidad social. el paradigma del tratamiento informativo de la violencia contra la mujer", Vivat Academia, v. 14, n. 119, pp. 58-70. Doi. http.//dx.doi.org/10.15178/va.2012.119.58-70

- (2013). "Vigencia y seguimiento de los códigos deontológicos monográficos sobre el tratamiento informativo de la violencia de género. el caso del diario Público", Ámbitos, n. 22. URL. http.//institucional.us.es/ambitos/?p=85 [Consultado el 03/03/2018] 
Deontología periodística en materia de violencias contra las mujeres ¿Quién elabora los documentos?...

Martínez-Sánchez, P. (2010). “Parte I. Encuestas”, en Fernández Arribas, J. y Noblejas, M. (eds.). Cómo informar sobre violencia contra la mujer en las relaciones de pareja. Valencia. Centro Reina Sofía, pp. 20-40.

Matud, M. P.; Rodríguez, C. y Espinosa, I. (2011). “Gender in Spanish Daily Newspapers”, Sex Roles, v. 64, n. 3-4, pp. 253-264. Doi. 10.1007/s11199-010-9874-3

Menéndez, M. I. (2014). "Retos periodísticos ante la violencia de género. El caso de la prensa local en España”, Comunicación y Sociedad, n. 22, pp. 53-77. Doi. https.//doi.org/10.32870/cys.v0i22.48

Ministerio de Sanidad, Política Social e Igualdad (2011). Encuesta de opinión sobre la violencia de género [en línea]. URL. http.//goo.gl/kmNlp [Consultado el 27/09/2018].

Organización Mundial de la Salud (OMS) (2013). Global and regional estimates of violence against women. prevalence and health effects of intimate partner violence and non-partner sexual violence. URL. http.//apps.who.int/iris/bitstream/handle/10665/85239/9789241564625_eng.pdf;jsessionid=DF4BC62F1E365CE9C773A1B070A12774?sequence=1 [Consultado el 08/10/2018].

Peris, M. (2016). "La representación rigurosa del origen de la violencia machista en la prensa escrita. una propuesta de medición”, Estudios sobre el Mensaje Periodístico, v. 22, n. 2, pp. 1123-1142. Doi. http.//dx.doi.org/10.5209/ESMP.54255

Roberto, K. A.; McCann, B. R. y Brossoie, N. (2013). "Intimate partner violence in late life. An analysis of national news reports", Journal of Elder Abuse and Neglect, v. 25, n. 3, pp. 230-241. Doi. http.//dx.doi.org/10.1080/08946566.2012.751825

Rodgers, S. y Thorson, E. (2003). "A Socialization Perspective on Male and Female Reporting”, Journal of Communication, v. 53, n. 4, pp. 658-675. Doi. https.//doi.org/10.1111/j.1460-2466.2003.tb02916.x

Ross, K. et al. (2018). "Women, Men and News", Journalism Studies, v. 19, n. 6, pp. 824-845. Doi. https.//doi. org/10.1080/1461670X.2016.1222884

Salter, M. (2013). “Justiceand revenge in online counter-publics. Emerging responses to sexual violencein the age of socialmedia", Crime, Media, Culture. An International Journal, v. 9, n. 3, pp. 225-242. Doi. https.//doi.org/10.1177/1741659013493918

Simons, M. y Khan, E. (2018). "Working with media to prevent violence against women the uncovered intervention", Australian Journalism Review, v. 40, n. 1, pp. 51-63. URL. https.//search.informit.com.au/documentSummary;d$\mathrm{n}=859308126055469 ;$ res=IELLCC;type=pdf [Consultado el 04/12/2018].

- y Morgan, J. (2018). “Changing Media Coverage of Violence Against Women”, Journalism Studies, v. 19, n. 8, pp. 1202-1217. Doi. https.//doi.org/10.1080/1461670X.2016.1266279

Soriano, J. (2004). “Las mujeres ante la información de violencia de género", Sphera Pública, n.4, pp. 151-170.

-; Cantón, M. J. y Díez, M. (2005). “La pseudofeminización de la profesión periodística en España”, Zer, n. 19, pp. 35-52.

Sutherland, G. et al. (2016). "Guidelines for Reporting on Violence Against Women in the News Media", Australian Journalism Review, v. 38, n. 1, pp. 5-17. URL. https.//ssrn.com/abstract=2832441 [Consultado el 14/05/2018].

Vega, A. (2014). "El tratamiento de la violencia contra las mujeres en los medios de comunicación", Comunicación y Medios, n. 30, pp. 9-25. Doi. 10.5354/0719-1529.2015.30332 
- (2018). "Violence against women in media and digital content", WACC Communication for all. URL. http.//waccglobal. org/articles/violence-against-women-in-media-and-digital-content [Consultado el 04/12/2018].

Valles, M. (1999). Técnicas cualitativas de investigación social. Reflexión metodológica y práctica profesional. Madrid. Síntesis.

Wozniak, J. y McCloskey, K. (2010). "Fact or fiction? Gender issues related to newspaper reports of intimate partner homicide", Violence Against Women, v. 16, n. 8, pp. 934-952. Doi. https.//doi.org/10.1177/1077801210375977

Zurbano-Berenguer, B. (2015a). "El tratamiento informativo y la responsabilidad ética en la información mediática de la violencia de género", En V Congreso para el Estudio de la Violencia contra las Mujeres. Sevilla. Consejería de Justicia e Interior, pp. 46-56. URL. https://idus.us.es/xmlui/handle/11441/40074

- (2015b). Discurso periodístico y violencias contra las mujeres. Aproximaciones a la construcción y valoración de los mensajes informativos en la prensa de referencia en España (2000-2012) (Tesis Doctoral). Sevilla. Universidad de Sevilla.

- (2018). "Comunicación, periodismo y violencias contra las mujeres en España: Reflexiones en torno a un estado de la cuestión”, Revista Observatorio, v. 4, n. 2, pp. 80-117. Doi. http://dx.doi.org/10.20873/uft.2447-4266.2018v4n2p80

- y García-Gordillo, M.M. (2017). "Propuesta metodológica para la evaluación de la calidad deontológica de las noticias sobre violencias contra las mujeres", Communication \& Society, v. 30, n. 1, pp. 73-85. Doi. 10.15581/003.30.1.73-85

- y Liberia-Vayá, I. (2013). “Análisis crítico de los discursos audiovisuales sobre la violencia de género contra las mujeres: estudio comparado de caso", Estudios sobre el Mensaje Periodístico, v. 19, n. 2, pp. 921-939. Doi. http://dx.doi.org/10.5209/ rev_ESMP.2013.v19.n2.43480

- y Liberia-Vayá, I. (2014). "Revisión teórico-conceptual de la violencia de género y de su representación en el discurso mediático: Una propuesta de resignificación", ZER, v. 19, n. 36, pp. 121-142. URL. http://www.ehu.eus/ojs/index.php/Zer/ article/view/13494/12080

- y Martínez-Fábregas, J. (2011). “Periodismo y Violencia de Género: la necesidad de un compromiso”, en Suárez-Villegas, J. C. (ed.). La ética de la comunicación a comienzos del siglo XXI. Sevilla: Eduforma, pp. 124-139. 
